\title{
Nanoparticle mediated controlled delivery of dual growth factors
}

\author{
ZHANG LuZhong $^{1 \dagger}$, ZHOU YouLang $^{2 \dagger}$, LI GuiCai $^{1}$, ZHAO YaHong ${ }^{1}$, GU XiaoSong ${ }^{1}$ \\ \& YANG YuMin ${ }^{1 *}$ \\ ${ }^{1}$ Jiangsu Key Laboratory of Neuroregeneration, Nantong University, Nantong 226001, China; \\ ${ }^{2}$ Hand Surgery Research Center, Department of Hand Surgery, Affiliated Hospital of Nantong University, Nantong 226001, China
}

Received August 3, 2013; accepted September 12, 2013; published online January 14, 2014

\begin{abstract}
Peripheral nerve functional recovery after nerve injury generally requires multiple growth factors by synergistic effect. However, the optical combination of multiple synergistic growth factors for axonal regeneration has been scarcely considered up to now. Meanwhile, the use of growth factors in promoting nerve regeneration was limited by its short biological half-life in vivo, its vulnerability to structure disruption or hydrolyzation, leading to loss of bioactivity. Herein, a novel polymeric nanoparticle delivery system composed of heparin and $\varepsilon$-poly-L-lysine (PL) was prepared for control release of nerve growth factor (NGF) and basic fibroblast growth factor (bFGF). The nanoparticles were synthesized by polyelectrolyte complexation in aqueous solution at room temperature, followed by cross-linking with biological genipin. The obtained nanoparticles had a spherical shape, with a mean diameter of about $246 \mathrm{~nm}$, and high growth factors encapsulation efficiency as well as good stability. NGF and bFGF were encapsulated in the nanoparticles and showed a continuous and slow release behavior in vitro. The bioactivities of the released growth factors were evaluated, and exhibited the synergistic effect. The controlled release of the dual synergistic growth factors would improve the treatment of peripheral nerve injury to mimic the natural cellular microenvironments.
\end{abstract}

control release, nerve growth factor, basic fibroblast growth factor, nanoparticles

Citation: Zhang LZ, Zhou YL, Li GC, Zhao YH, Gu XS, Yang YM. Nanoparticle mediated controlled delivery of dual growth factors. Sci China Life Sci, 2014, 57: 256-262, doi: 10.1007/s11427-014-4606-5

Peripheral nerve injury is a critical and devastating condition that is usually caused by traumatic injury and often results in life-long disability, for example, permanent functional and sensory deficits [1]. When the long peripheral nerve defect cannot be repaired by end-to-end suturing, a nerve graft between the proximal and distal nerve stumps is often necessary for promoting the nerve regeneration $[1,2]$. The representative nerve graft selection is an autologous nerve graft self-donated from another part of the body. However, this recognized gold standard technique compared with other treatments for peripheral nerve repair is limited by the inherent drawbacks, such as secondary injury

$\dagger$ Contributed equally to this work

*Corresponding author (email: yangym@ntu.edu.cn) at the donor site, tissue availability, formation of neuroma, and the mismatch between nerve and graft in tissue structure and size [3]. To overcome these disadvantages of autologous nerve graft, various biochemical engineering of nerve guidance conduits based on artificial or natural materials has emerged as an alternative choice to bridge nerve gaps [4-6]. These guidance conduits have significant merits in peripheral nerve repair, such as no need for a second surgery, assistance in guiding the regenerating axons from the proximal to distal stumps and minimizing the infiltration of fibrous scar tissue [7]. At present, these nerve guidance conduits for the treatment of peripheral nerve injuries have limited functional capacity to repair short nerve defect [8]. However, this method often results in the deficient clinical results or the entire failure of nerve regeneration in the case 
of longer nerve gap. One of the main causes of the poor clinical nerve regeneration is inadequate growth factors support in the nerve regeneration microenvironments [9]. Accordingly, increasing functional requirements for nerve conduit become necessary since they should not only serve as a desirable support but also a satisfactory carrier to achieve suitable functional recovery for long nerve defect. For improving the function of nerve guides, the bioactive strategy containing growth factors is investigated to mimic the natural cellular microenvironments $[10,11]$.

Growth factors are naturally occurring proteins and polypeptides that could stimulate the cellular survival, proliferation and differentiation [12]. Growth factors also play an important role for neuronal survival and axonal regeneration via the binding to specific classes of tyrosine kinase receptors existing on the surface of the responsive cells, which is a prerequisite for effective reinnervation of the injured nerves $[1,13]$. They have been widely used in tissue engineering approaches for the repair of peripheral nerve injuries and nerve defects. Two of the attractive factors are nerve growth factor (NGF) and basic fibroblast growth factor (bFGF). NGF could promote the growth, maintenance and survival of sensory and motor neuron, and regulate the synthesis of protein and metabolism of sugar and fat in the neuron [14]. bFGF is a representative member of the heparin-binding growth factors, and could promote the survival and neurite extension of neurons from the central nervous system in vitro, stimulating proliferation of the glial cells such as astrocytes, oligodendrocytes, and schwann cells $[15,16]$. Much evidence has indicated that after nerve injury the local presence of growth factor at the injury sites plays a vital and complex role in controlling the survival, proliferation, migration and differentiation of various cell types involved in nerve regeneration [17]. Additionally, recent studies demonstrated that the optimal combination of multiple growth factors elicits synergistic effect on axonal regeneration in vitro and in vivo [18]. It could be ascribed to that single factor treatment may not be optimal as nerves generally comprise different neuronal subpopulations that depend on different growth factors. However, the optical combination of multiple synergistic growth factors for axonal regeneration has been scarcely considered up to now.

The growth factors could be generally delivered by direct injection or release from a carrier. When the growth factors were administrated by direct injection, their applications were limited by their short biological half-life in vivo, their vulnerability to structure disruption or hydrolyzation, leading to loss of bioactivity at the defect site [19]. Moreover, growth factors also show minimal tissue penetration which may result in ineffective delivery at the defect site [20]. Among the strategies developed to improve protein's bioavailability and absorption, the use of colloidal carriers, especially nanoparticle delivery carriers, is an emerging strategy under investigation [21]. Compared with the direct administration, the growth factors encapsulated within the carriers can be more efficiently used than free growth factors, and therefore, the amount of growth factors required can be reduced. Furthermore, nanoparticle drug delivery carriers, owing to their sub-cellular and sub-micron size, could easily penetrate into tissues and fine capollaries and control the dosage and delivery period of biomolecules with the purpose of enhancing the efficacy of the growth factors [22]. These drug delivery systems are developed not only to improve the biological utilization of growth factors by controlling drug release to the target site, but also to protect their bioactivity from degradation by direct exposure to the harsh environments. Therefore, increasing interests and intensive efforts have been devoted to biomedical drug delivery carriers composed of biodegradable and biocompatible natural polymer at the nanoscale.

In this study, a novel polymeric nanoparticle delivery system composed of heparin and $\varepsilon$-Poly-L-lysine (PL) was prepared for control release of the growth factors. The heparin-PL nanoparticles were synthesized by polyelectrolyte complexation in aqueous solution at room temperature, followed by cross-linking with biological genipin. The nanoparticles were characterized by dynamic light scattering (DLS), transmission electron microscopy (TEM) and scanning electron microscopy (SEM). NGF and bFGF were loaded in the nanoparticles with high encapsulation efficiency and showed a continuous and slow release behavior in vitro. The bioactivities of the released growth factors were evaluated by the number of neurite-bearing PC12 cells. It is demonstrated that two growth factors could elicit the synergistic effect on the neurite growth of PC12 cells.

\section{Materials and methods}

\subsection{Materials}

$\varepsilon$-Poly-L-lysine (PL, $n=25-35$ ) was purchased from Zhejiang Silver Elephant Bioengineering Co., Ltd. (China). Heparin (Mw, 6000-20000) was bought from Shanghai Yuanye Reagent Company. Genipin was supplied by Shanghai Aladdin Reagent Company. Nerve growth factor 7.0s (NGF) was purchased from EMD Millipore Corporation. Recombinant human basic fibroblast growth factor (bFGF) was purchased from PeproTech, Inc (Rocky Hill, USA). Mouse NGF enzyme-linked immunosorbent assay (ELISA) kit and human bFGF ELISA kit were purchased from Shanghai Yuanye Reagent Company, China. All other reagents were of analytical purity grade and used without further purification.

\subsection{Preparation of heparin-PL nanoparticles}

In a typical run, $\mathrm{PL}$ solution $\left(1 \mathrm{~mL}\right.$ of a $3 \mathrm{mg} \mathrm{mL}^{-1}$ aqueous solution) was added dropwise to $2 \mathrm{~mL}$ of heparin aqueous solution $\left(3 \mathrm{mg} \mathrm{mL}^{-1}\right)$ under stirring, and the mixture was 
stirred for $1 \mathrm{~h}$ at room temperature. Genipin $(2.3 \mathrm{mg})$ was then added to the reaction system at room temperature and cross-linked for $12 \mathrm{~h}$. After cross-linking, the aggregates were removed by passing the solution through a $0.22 \mu \mathrm{m}$ filter. The nanoparticles were collected by centrifugation at $10000 \mathrm{r} \mathrm{min}^{-1}$ and redispersed in the predetermined volume of distilled water.

\subsection{Preparation of growth factors loaded nanoparticles}

Briefly, PL solution ( $1 \mathrm{~mL}$ of a $3 \mathrm{mg} \mathrm{mL}^{-1}$ aqueous solution containing NGF $(0.5 \mu \mathrm{g})$ and $\operatorname{bFGF}(0.5 \mu \mathrm{g}))$ was added dropwise to $2 \mathrm{~mL}$ of heparin aqueous solution $\left(3 \mathrm{mg} \mathrm{mL}^{-1}\right)$ under stirring, and the mixture was stirred for $1 \mathrm{~h}$ at room temperature. Genipin $(2.3 \mathrm{mg})$ was then added to the reaction system at room temperature and cross-linked for $12 \mathrm{~h}$. After cross-linking, the aggregates were removed by passing the solution through a $0.22 \mu \mathrm{m}$ filter. The nanoparticles were collected by centrifugation at $10000 \mathrm{r} \mathrm{min}^{-1}$ and redispersed in the predetermined volume of distilled water.

Similarly, the bFGF loaded nanoparticles or NGF loaded nanoparticles were prepared by adding PL solution containing $1 \mu \mathrm{g}$ bFGF or $1 \mu \mathrm{g}$ NGF to the heparin solution and cross-linked as described above.

\subsection{Characterization of nanoparticles}

Particle size of the nanoparticles we carried out using a dynamic light scattering instrument (Brookhaven Instruments Corporation, USA). Each sample of the nanoparticles was adjusted to a concentration of $0.05 \%(\mathrm{w} / \mathrm{v})$ in filtered water or $0.01 \mathrm{~mol} \mathrm{~L}^{-1} \mathrm{NaCl}$ solution in the case of zeta potential examination. All analyses were performed in triplicate at $25^{\circ} \mathrm{C}$ and the results were the average of the three runs. The morphology of prepared nanoparticles was examined by transmission electron microscopy (TEM; JEOL JEM-1010). $10 \mu \mathrm{L}$ of the nanoparticle suspension was placed onto a 200-mesh carbon-coated copper grid for $2 \mathrm{~min}$, and after air-drying the samples were observed. Scanning electron microscopy (SEM) observations were performed on HITACHI S-4800.

\subsection{Growth factor encapsulation efficiency}

The encapsulation efficiency of growth factors in the nanoparticles with different formations was determined by centrifuging the nanoparticle suspension at $10000 \mathrm{r} \mathrm{min}^{-1}$ at $4^{\circ} \mathrm{C}$ for $30 \mathrm{~min}$. The amount of growth factor in clear supernatant was determined using the ELISA using a preestablished calibration curve. The encapsulation efficiency was calculated by the following formulas:

$$
\begin{aligned}
& \text { Encapsulation efficiency } \% \\
& =\frac{\text { weight of growth factor in the nanoparticles }}{\text { weight of the feeding growth factor }}
\end{aligned}
$$

\subsection{In vitro release of the growth factors loaded nano- particles}

A suspension of the growth factors loaded nanoparticles in water was dialyzed against $10 \mathrm{~mL}$ of phosphate buffer solution (PBS, $0.01 \mathrm{~mol} \mathrm{~L}^{-1}$ ) with different $\mathrm{pH}$ values at $37^{\circ} \mathrm{C}$. After a predetermined period, $1 \mathrm{~mL}$ aliquots was withdrawn and the nanoparticles were centrifuged at $10000 \mathrm{r} \mathrm{min}^{-1}$ at $4^{\circ} \mathrm{C}$ for $30 \mathrm{~min}$. The growth factor concentration in sampled release medium was determined by ELISA using a pre-established calibration curve. The measurements were performed in triplicate and the results were the average of the three times.

\subsection{In vitro cytotoxicity}

The cytotoxicity of samples were tested by using a MTT (3-(4,5-dimethylthiazol-2-yl)-2,5-diphenyltetrazolium bromide) assay. Rat Schwann cell line (RSC-96) cells were grown in a Dulbecco's modified Eagle's medium (DMEM) with $2 \mathrm{mmol} \mathrm{L}^{-1}$ glutamine, $100 \mathrm{U} \mathrm{mL}^{-1}$ penicillin and 100 $\mu \mathrm{g} \mathrm{mL}^{-1}$ streptomycin. The culture medium was supplemented with $10 \%$ fetal bovine serum in a $5 \% \mathrm{CO}_{2}$ atmosphere at $37^{\circ} \mathrm{C}$. The cells were seeded into a 96-well plate, and incubated with $100 \mu \mathrm{L}$ of culture medium containing a series of doses of samples at $37^{\circ} \mathrm{C}$ for $24 \mathrm{~h}$. After incubation, the culture media in each well were removed and cells were washed three times with PBS. Then, $20 \mu \mathrm{L}$ of MTT solutions $\left(5 \mathrm{mg} \mathrm{mL}^{-1}\right)$ was added to each well and cultured for another $4 \mathrm{~h}$. The supernatant was discarded and $100 \mu \mathrm{L}$ of DMSO was added to each well. The $A$ values of plates were observed on a microplate reader at $570 \mathrm{~nm}$ (Safire, Tecan, Switzerland).

\subsection{NGF and bFGF bioactivity by PC12 cell bioassay}

Rat PC12 cells were grown in DMEM with $2 \mathrm{mmol} \mathrm{L}^{-1}$ glutamine, $100 \mathrm{U} \mathrm{mL}^{-1}$ penicillin and $100 \mu \mathrm{gL}^{-1}$ streptomycin. The culture medium was contained with $10 \%$ horse serum and $5 \%$ fetal bovine serum in a $5 \% \mathrm{CO}_{2}$ atmosphere at $37^{\circ} \mathrm{C}$. Prior to differentiation of the PC12 cells, the well plate was coated with poly-L-lysine overnight. The cells were seeded into a 24 -well plate and incubated with the culture medium at $37^{\circ} \mathrm{C}$ cultured for $7 \mathrm{~d}$. The culture medium consisted of DMEM medium supplemented with various samples: control group, blank nanoparticles, NGF (100 $\mathrm{ng} \mathrm{mL} \mathrm{m}^{-1}$ ), NGF loaded nanoparticles (NGF, $100 \mathrm{ng} \mathrm{mL}^{-1}$ ), bFGF (100 ng mL ${ }^{-1}$ ), bFGF loaded nanoparticles (bFGF, $100 \mathrm{ng} \mathrm{mL}{ }^{-1}$ ), NGF+bFGF (NGF, 100 ng mL ${ }^{-1}$; bFGF, 100

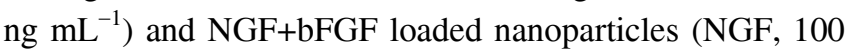
ng $\mathrm{mL}^{-1}$; bFGF, $100 \mathrm{ng} \mathrm{mL}^{-1}$ ). Fresh growth factor formulations were added to the media every two days. 


\subsection{Immunocytochemistry}

Cultured cells were fixed in freshly prepared $4 \%$ paraformaldehyde for $10 \mathrm{~min}$ at room temperature, and then permeabilized with $0.1 \%$ triton $\mathrm{X}-100 / \mathrm{PBS}$ for $15 \mathrm{~min}$. After washing three times with PBS for $10 \mathrm{~min}$, the cells were blocked with $10 \%$ BSA (blocking buffer) for $45 \mathrm{~min}$ at room temperature. Cells were incubated with mouse monoclonal $\beta$-tubulin III and rabbit anti-neurofilament (NF) 200 $\mathrm{IgG}$ fraction of antiserum for $2 \mathrm{~h}$ followed by further reaction with Alexa Fluor 488 donkey anti-mouse IgG and Alexa Fluor 594 donkey anti-rabbit IgG. Afterwards, the cells were stained by DAPI for $10 \mathrm{~min}$. Representative fluorescent images were observed using a Leika fluorescence microscope.

\section{Results and discussion}

\subsection{Preparation of heparin-PL nanoparticles}

In order to develop the effective method to deliver growth factors, a reaction nanoparticulate system was selected in aqueous solution consisting of a cationic biomacromolecule, PL, and an anionic biomacromolecule, heparin. Due to their well-established properties, such as water-solubility, biodegradability and high biocompatibility, PL and heparin were chosen as the starting material in the design of vectors for growth factors delivery [23,24]. Furthermore, heparin could have specific affinity with many growth factors and then has been widely utilized for growth factor delivery to optimize and extend the growth factor delivery kinetics, prevent their degradation and enhance binding to cell surface receptors $[25,26]$. Additionally, it was previously reported that heparin improves the axonal growth in the peripheral nerve injury [27].

The heparin-PL nanoparticles were prepared by polyelectrolyte complexation and covalent cross-link with genipin in aqueous solution at room temperature, as schematically shown in Figure 1A. The driving force of the formation of the nanoparticles can be ascribed to the complexation through the intermolecular electrostatic interaction between the polycationic PL with the polyanionic heparin. Subsequently, the nanoparticles were crosslinked by biological genipin, which is superior to traditional crosslinking agents in terms of lower cytotoxicity and has proven to have neuritogenic activity and neuroprotective effects [28,29].

\subsection{Characterization of heparin-PL nanoparticles}

The mean hydrodynamic diameter of the obtained nanoparticles was determined to be $246 \mathrm{~nm}$ in aqueous medium of pH 7.4 by DLS (Figure 1B), suggesting that the particles are well dispersed in aqueous solution. The morphology and structure of the formed nanoparticles were examined by TEM and SEM (Figure 2). It can be seen that all of the na-
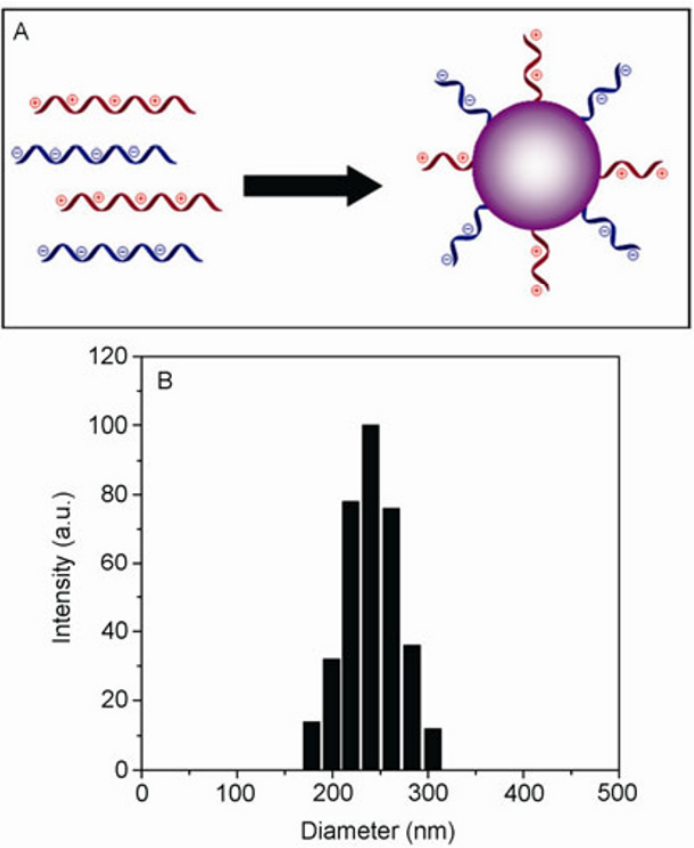

Figure 1 A, Schematic diagram of the preparation of the nanoparticles. B, Hydrodynamic diameter distribution of the genipin cross-linked PLheparin nanoparticles determined by DLS.
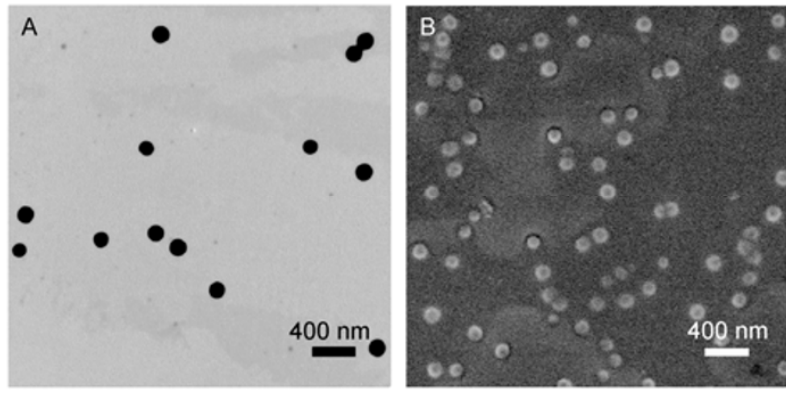

Figure 2 TEM (A) and SEM (B) image of the genipin cross-linked PL-heparin nanoparticles.

noparticles exhibited a spherical shape with a narrowly distributed diameter of $230 \mathrm{~nm}$, which is smaller than the hydrodynamic diameter determined by DLS due to the dry state in the TEM observation.

To confirm the chemical structure of the particles, Fourier transform infrared (FTIR) spectroscopic analysis of PL, heparin and PL-heparin nanoparticles was performed. Figure 3 shows the FTIR spectra of PL, heparin, genipin cross-linked PL-heparin nanoparticles. In the spectrum of PL, the characteristic peak at $1673 \mathrm{~cm}^{-1}$ corresponds to the carbonyl stretching of secondary amide (amide I band) and a peak at $1560 \mathrm{~cm}^{-1}$ is attributed to the N-H bending vibrations. The peaks located at 3402 and $1620 \mathrm{~cm}^{-1}$ could be assigned to the hydroxyl stretching vibration and the carbonyl stretching vibration, respectively. The spectrum of the PL-heparin nanoparticles had characteristic peaks similar to the parent molecules. However, some minor changes in the 


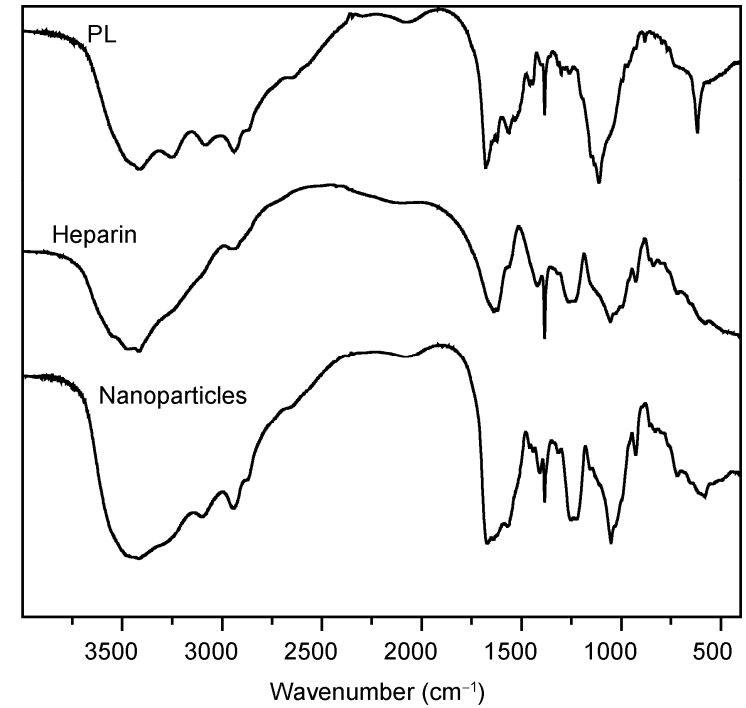

Figure 3 FTIR spectra of PL, heparin, and PL-heparin nanoparticles.

spectrum were observed, for example, the absorption band at 1673 and $1620 \mathrm{~cm}^{-1}$ became wider in the nanoparticles. These data indicated significant ionic interaction between the PL and heparin molecules.

\subsection{In vitro release from nanoparticles}

Considering that the heparin could bind a multitude of growth factors and maintain their bioactivity for an extended period of time [30], the PL-heparin nanoparticles seem to be very appropriate to be the carriers for growth factor delivery. To evaluate the potential of PL-heparin nanoparticles as a drug delivery system, the growth factors were loaded into the nanoparticles. Consequently, we successfully encapsulated the NGF and bFGF into the nanoparticles by their specific binding with heparin. PL solution containing growth factors was added to heparin solution to prepare the particles, and then the particles were cross-linked with genipin. A satisfactory encapsulation efficiency of NGF and bFGF was found to be about $98.1 \%$ and $99.3 \%$, respectively. The size distribution of growth factor loaded particles did not significantly change compared with that of the unloaded nanoparticles (data not shown), since the ratio of growth factor in the particles is small.
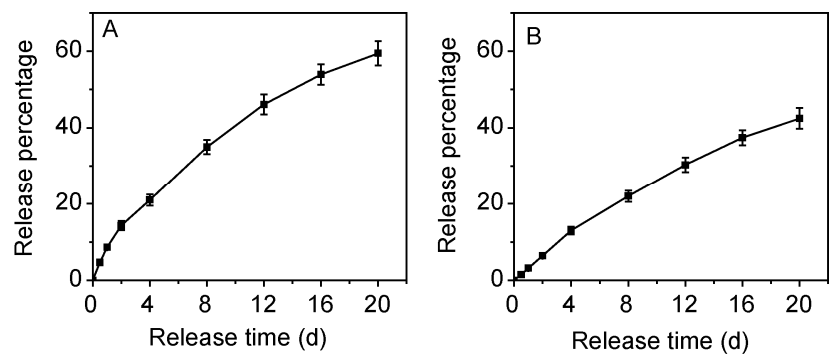

Figure 4 In vitro release profiles of NGF (A) and bFGF (B) released from nanoparticles.
The in vitro release of growth factors from nanoparticles was examined. Figure 4 shows the cumulative in vitro release profiles up to 20 days of growth factors from the particles in release medium at $37^{\circ} \mathrm{C}$. A sustained and no initial burst in vitro release profile of growth factors (NGF and bFGF) from the particles was observed, which may be ascribed to the strong binding between particles and growth factors. Since heparin has specific affinity with many growth factors, such as NGF and bFGF, the mechanism for growth factor release from particles is quite different from that of physically or electrostatically encapsulating growth factors which usually have much larger initial burst from the nanoparticles [31]. For the bFGF, $\sim 42.5 \%$ of the loaded growth factor was released from particles within 20 days. However, $\sim 59.4 \%$ of the loaded growth factor was released from particles within 20 days for the NGF. This phenomenon can be attributed to the different binding constants between heparin and growth factors (bFGF has the high affinity binding with proteoglycan heparin via specific electrostatic interaction. However, NGF has the low affinity with proteoglycan heparin) [32,33]. This result suggests that growth factors loaded nanoparticles show a continuous and slow release behavior for NGF and bFGF.

\subsection{In vitro cytotoxicity of nanoparticles}

To examine the cytotoxicity of the growth factors loaded nanoparticles, the in vitro cytotoxicity tests against the RSC-96 cells were conducted. The RSC-96 cells were cultivated in the DMEM culture medium with various concentrations of nanoparticles for $24 \mathrm{~h}$ (Figure 5). It is found that the viability of RSC-96 cells cultured in the nanoparticle solution was not significantly different from that in DMEM supplemented with $10 \%$ fetal calf serum (blank control), which indicated that the nanoparticles have no obvious cytotoxic effect at all used conditions. However, the viability of cells cultured with the medium containing growth factors loaded nanoparticles is higher than that of the nanoparticle group, since the growth factor may promote the survival and proliferation of schwann cells. Furthermore, the cells that were observed with optical microscopy after $12 \mathrm{~h}$ in culture in the solution were still active. Bright-field images show that all cells proliferate very well and maintain their normal configuration at all used conditions (data not shown).

\subsection{In vitro bioactivity of nanoparticles}

To examine whether the released growth factors is still biologically active, the in vitro bioactivity tests of growth factors against PC12 cells were conducted. PC12 cells originated from pheochromocytoma of a rat adrenal medulla, sprout neuritis and differentiate into sympathetic ganglion-like cell in response to growth factors. Therefore, this model is usually used to evaluate the neuronal differentiation. 


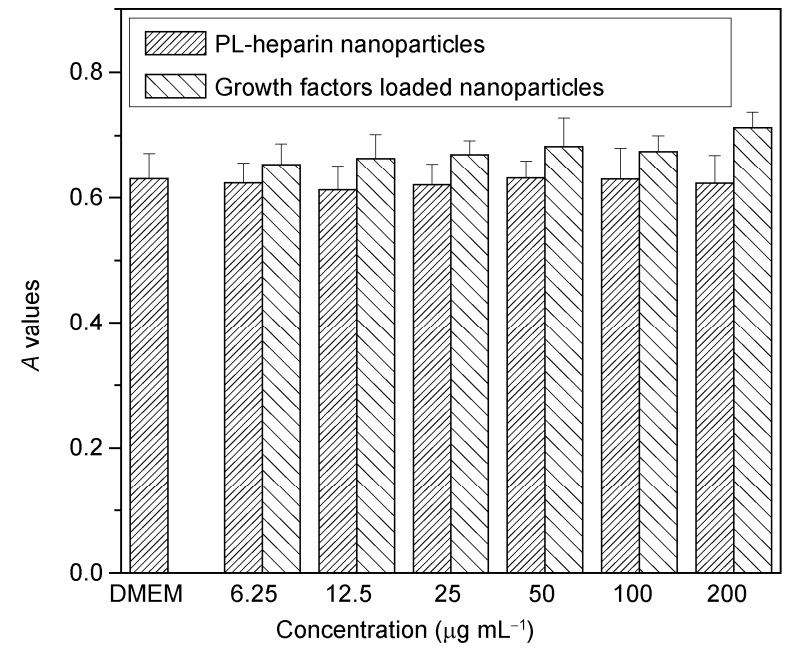

Figure 5 In vitro cytotoxicity of PL-heparin nanoparticles and growth factors loaded nanoparticles against RSC-96 cells.

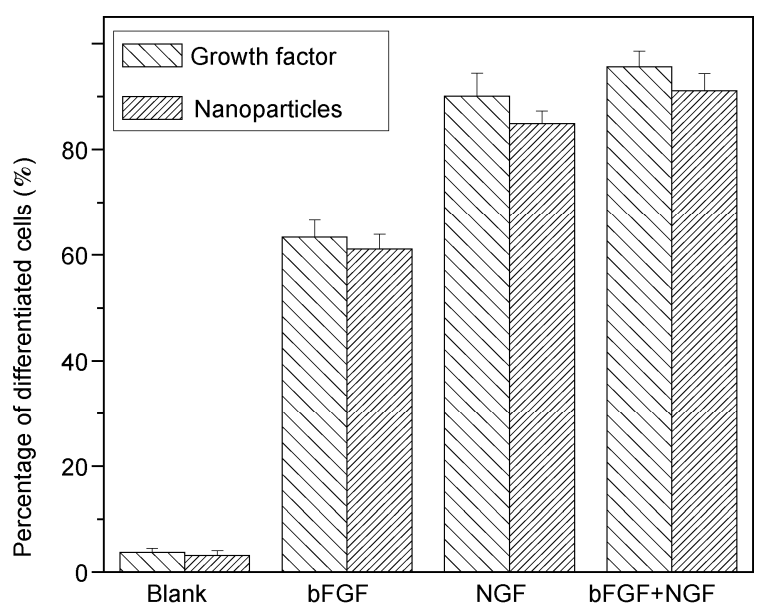

Figure 6 The percentage of neurite-bearing PC12 cells in whole population treated with various samples after seven days culture.

The neurite outgrowth of PC12 cells was investigated by counting the number of neurite-bearing PC12 cells (Figure $6)$. After seven days culture, the percentage of neuritebearing (differentiated) cells treated with blank nanoparticles or DMEM medium is small. When cells were treated with growth factor, the percentage of neurite-bearing cells increased dramatically. Interestingly, the percentage of neurite-bearing cells treated with combination of bFGF and NGF has the highest ratio in all used groups. The synergistic effect of the combined growth factors enables the higher neurite-bearing percentage. Meanwhile, the cells treated with the growth factor loaded nanoparticles exhibited similar results. However, the nanoparticle group showed a little lower percentage than free growth factors at equal concentration after seven days culture at the tested concentration. This phenomenon can be attributed to the sustained release property of growth factors loaded nanoparticles.

To confirm the differentiation from PC12 cells to the neuronal cell phenotype, the cultured cells were fixed and immunostained with two neuronal markers, $\beta$-tubulin III and NF200 (Figure 7). It is shown that PC12 cells treated with blank nanoparticles and control group have not differentiated to sympathetic ganglion-like cells. In contrast, significant differentiation appears when PC12 cells were treated with growth factor or growth factor loaded nanoparticles. The neurite length of PC12 cells treated with combination of NGF and bFGF was longer than that of cells treated with single growth factor. The neurite length of PC12 cells treated with NGF is longer than that treated with bFGF [34]. Additionally, the nanoparticle groups displayed the similar trends concerning the percentage of neurite-bearing cells treated with nanoparticles. The immunocytochemical analysis indicated that combination of NGF and bFGF has synergistic effect on the differentiation of PC12 cells.

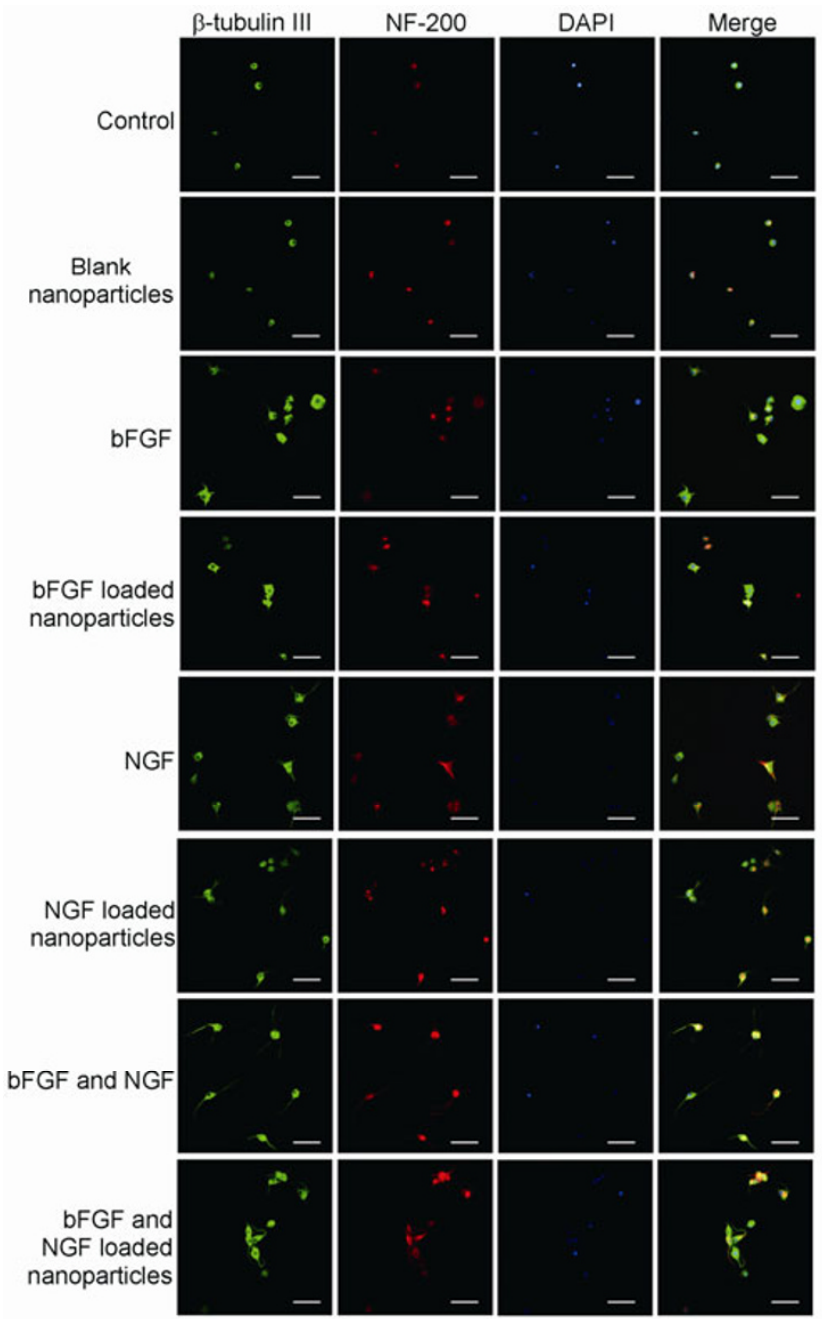

Figure 7 Immunocytochemical fluorescence images of differentiated PC12 cells 7 days after treated with various samples. For each panel, the images from left to right show $\beta$-tubulin III fluorescence in cells (green), NF-200 fluorescence in cells (red), cell nuclei stained by DAPI (blue), and overlays of the above images. Scale bar, $100 \mu \mathrm{m}$. 


\section{Conclusion}

The novel polymeric nanoparticle delivery system composed of heparin and PL was prepared for controlled release of NGF and bFGF. The nanoparticles were fabricated by polyelectrolyte complexation method, followed by crosslinking with biological genipin. NGF and bFGF were encapsulated in the nanoparticles and show a continuous and slow release behavior in vitro. The bioactivity of the released growth factors was evaluated, and exhibited the synergistic effect. The controlled release of the dual synergistic growth factors would improve the treatment of peripheral nerve injury to mimic the natural cellular microenvironments.

This work was supported by the National High Technology Research and Development Program of China (2012AA020502), National Natural Science Foundation of China (81171457, 81371687), Natural Science Foundation of Jiangsu Province of China (BK20130390), Natural Science Foundation of Nantong City (BK2012089), the Natural Science Research Program of Jiangsu Education Department (13KJB310014), the Priority of Academic Program Development of Jiangsu Higher Education Institutions and Natural Science Foundation of Nantong University (10Z014).

1 Konofaos P, Halen JPV. Nerve repair by means of tubulization: past, present, future. J Reconstruct Microsurg, 2013, 29: 149-163

2 Wang XD, Hu W, Cao Y, Yao J, Wu J, Gu XS. Dog sciatic nerve regeneration across a 30-mm defect bridged by a chitosan/PGA artificial nerve graft. Brain, 2005, 128: 1897-1910

3 Evans GR. Challenges to nerve regeneration. Semin Surg Oncol, 2000, 19: 312-318

4 Huang W, Begum R, Barber T, Ibba V, Tee NC, Hussain M, Arastoo M, Yang Q, Robson LG, Lesage S, Gheysens T, Skaer NJ, Knight DP Priestley JV. Regenerative potential of silk conduits in repair of peripheral nerve injury in adult rats. Biomaterials, 2012, 33: 59-71

5 Lee BK, Ju YM, Cho JG, Jackson JD, Lee SJ, Atala A, Yoo JJ. Endto-side neurorrhaphy using an electrospun PCL/collagen nerve conduit for complex peripheral motor nerve regeneration. Biomaterials, 2012, 33: 9027-9036

6 Khaing ZZ, Schmidt CE. Advances in natural biomaterials for nerve tissue repair. Neurosci Lett, 2012, 519: 103-114

7 Belkas JS, Shoichet MS, Midha R. Axonal guidance channels in peripheral nerve regeneration. Oper Tech Orthop, 2004, 14: 190-198

8 Pabari A, Yang SY, Seifalian AM, Mosahebi A. Modern surgical management of peripheral nerve gap. J Plastic Reconstruct Aesthet Surg, 2010, 63: 1941-1948

9 Daly W, Yao L, Zeugolis D, Windebank A, Pandit A. A biomaterials approach to peripheral nerve regeneration: bridging the peripheral nerve gap and enhancing functional recovery. J Royal Soc Interface, 2012, 9: 202-221

10 Ho PR, Coan GM, Cheng ET, Niell C, Tarn DM, Zhou H, Sierra D, Terris DJ. Repair with collagen tubules linked with brain-derived neurotrophic factor and ciliary neurotrophic factor in a rat sciatic nerve injury model. Arch Otolaryngol Head Neck Surg, 1998, 124: 761-766

11 Aebischer P, Salessiotis AN, Winn SR. Basic fibroblast growth factor released from synthetic guidance channels facilitates peripheral nerve regeneration across long nerve gaps. J Neurosci Res, 1989, 23: 282-289

12 Gu X, Ding F, Yang Y, Liu J. Construction of tissue engineered nerve grafts and their application in peripheral nerve regeneration. Prog Neurobiol, 2011, 93: 204-230
13 Lundborg G. A 25-year perspective of peripheral nerve surgery: evolving neuroscientific concepts and clinical significance. J Hand Surg Am, 2000, 25: 391-414

14 Flight MH. Neurotrophic factors: ride back to the nucleus. Nat Rev Neurosci, 2011, 12: 550-551

15 Davis JB, Stroobant P. Platelet-derived growth factors and fibroblast growth factors are mitogens for rat Schwann cells. J Cell Biol, 1990, 110: $1353-1360$

16 Torigoe K, Hashimoto K, Lundborg G. A role of migratory Schwann cells in a conditioning effect of peripheral nerve regeneration. Exp Neurol, 1999, 160: 99-108

17 Madduri S, Gander B. Growth factor delivery systems and repair strategies for damaged peripheral nerves. J Contr Release, 2012, 161: 274-282

18 Madduri S, Papaloizos M, Gander B. Synergistic effect of GDNF and NGF on axonal branching and elongation in vitro. Neurosci Res, 2009, 65: 88-97

19 Zeng W, Huang J, Xiao W, Rong M, Yuan Z, Luo Z. Ionically cross-linked chitosan microspheres for controlled release of bioactive nerve growth factor. Int J Pharm, 2011, 421: 283-290

20 Dyondi D, Webster TJ, Banerjee R. A nanoparticulate injectable hydrogel as a tissue engineering scaffold for multiple growth factor for multiple growth factor delivery for bone regeneration. Int $\mathrm{J}$ Nanomed, 2013, 8: 47-59

21 Zhang Y, Chan HF, Leong KW. Advanced materials and processing for drug delivery: the past and the future. Adv Drug Deliv Rev, 2013, 65: $104-120$

22 Liu JM, Wang X, Marin-Muller C, Wang H, Lin PH, Yao Q, Chen C. Current advances in research and clinical application of PLGA-based nanotechnology. Expert Rev Mol Diagn, 2009, 9: 325-341

23 Shukla SC, Singh A, Pandey AK, Mishra A. Review on production and medical applications of epsilon-polylysine. Biochem Eng J, 2012, 65: 70-81

24 Lin $\mathrm{YH}$, Chang $\mathrm{CH}$, Wu YS, Hsu YM, Chiou SF, Chen YJ. Development of $\mathrm{pH}$-responsive chitosan/heparin nanoparticles for stomach-specific anti-Helicobacter pylori therapy. Biomaterials, 2009, 30: $3332-3342$

25 Chu HH, Johnson NR, Mason NS, Wang YD. A [polycation:heparin] complex releases growth factors with enhanced bioactivity. J Contr Release, 2011, 150: 157-163

26 Goncalves NP, Oliveira H, Pego AP, Saraiva MJ. A novel nanoparticle delivery system for in vivo targeting of the sciatic nerve: impact on regeneration. Nanomedicine, 2012, 7: 1167-1180

27 Chau CH, Shum DK, Chan YS, So KF. Heparan sulphates upregulate regeneration of transected sciatic nerves of adult guinea-pigs. Eur $\mathbf{J}$ Neurosci, 1999, 11: 1914-1926

28 Yang YM, Zhao WJ, He JH, Zhao YH, Ding F, Gu XS. Nerve conduits based on immobilization of nerve growth factor onto modified chitosan by using genipin as a crosslinking agent. Eur $\mathbf{J}$ Pharm Biopharm, 2011, 79: 519-525

29 Mi FL, Tan YC, Liang HF, Sung HW. In vivo biocompatibility and degradability of a novel injectable-chitosan-based implant. Biomaterials, 2002, 23: 181-191

30 Zern BJ, Chu HH, Wang YD. Control growth factor release using a self-assembled [polycation:heparin] complex. PLoS ONE, 2010, 5: e11017

31 Stanwick JC, Baumann MD, Schoichet MS. Enhanced neurotrophin3 bioactivity and release from a nanoparticle-loaded composite hydrogel. J Contr Release, 2012, 160: 666-675

32 Sakiyama-Elbert SE, Hubbell JA. Controlled release of nerve growth factor from a heparin-containing fibrin-based cell ingrowth matrix. J Contr Release, 2000, 69: 149-158

33 Freeman I, Kedem A, Cohen S. The effect of sulfation of alginate hydrogels on the specific binding and controlled release of heparin-binding proteins. Biomaterials, 2008, 29: 3260-3268

34 Chung J, Kubota H, Ozaki Y, Uda S, Kuroda S. Timing-dependent actions of NGF required for cell differentitation. PLoS ONE, 2010, 5: e9011

Open Access This article is distributed under the terms of the Creative Commons Attribution License which permits any use, distribution, and reproduction in any medium, provided the original author(s) and source are credited. 